\title{
A BOTTLE AND DROPPER FOR OILY ESERINE
}

BY

\section{J. FOSTER}

LEEDS

This bottle was originally produced because I had to insert eserine in the eyes of so many patients, in a semi-dark room. The top and the glass rods of an ordinary eserine bottle were always getting mislaid or broken in the semi-darkness, and it was impossible to dispense with a top as the bottle got so dusty.
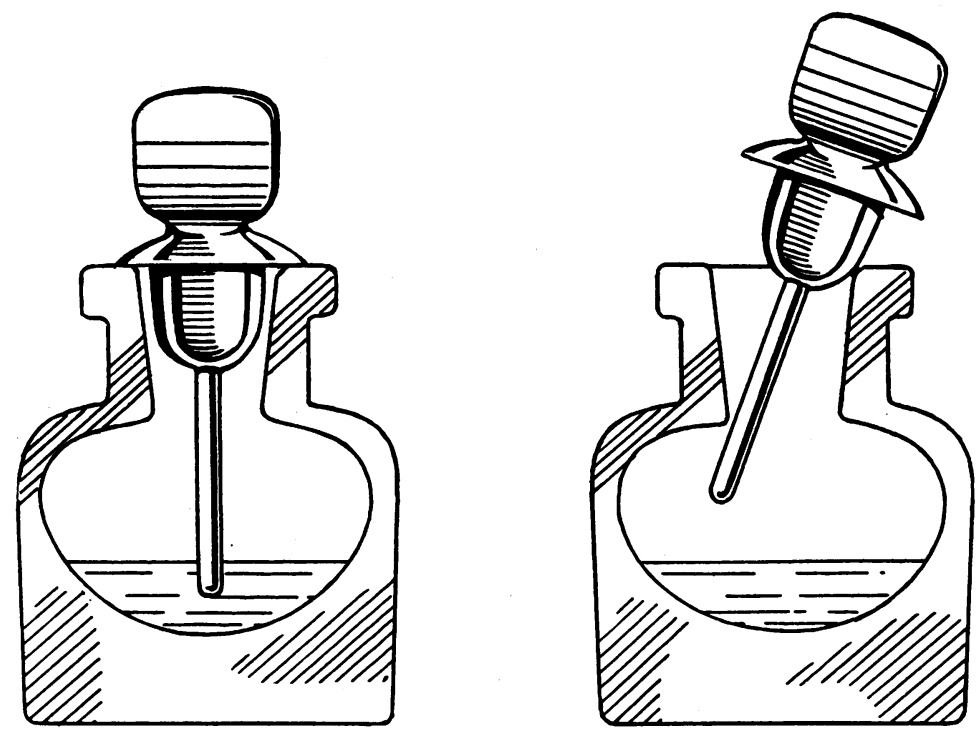

The present bottle (which is shown in its natural size in the diagram) has a stopper made of stainless steel. This was so designed that if put in obliquely, it falls into place, and the overhanging rim of the stopper dispenses with the need for a dust cover.

The stopper is virtually unbreakable, easily. held, and if the solution is kept at the proper level, there is enough oily eserine on the surface when withdrawn to form one or two drops for insertion into the eye. The bottle is made by Thackray \& Sons, Leeds. 